\title{
A Caridade criando hospitais em Minas Gerais (Brasil) - séculos XVIII-XX
}

\author{
Rita de Cássia Marques (*) \\ $\left({ }^{*}\right)$ Universidade Federal de Minas Gerais (UFMG) - Brasil. \\ rcmarques63@yahoo.com.br
}

Dynamis

[0211-9536] 2011; $31(1): 107-129$
Fecha de recepción: 2 de febrero de 2010

Fecha de aceptación: 18 de diciembre de 2010

SUMÁRIO: 1.-Introdução. 2.-A renovação do discurso da caridade/misericórdia: o caso dos vicentinos. 3.-Cidade salubre não precisa de hospitais? 4.-Associação de Médicos Católicos.

RESUMO: O artigo é fruto de uma pesquisa sobre o Patrimônio Cultural da Saúde em Minas Gerais (Brasil) e se dedica a compreender a construção de hospitais fomentados pelas ações caritativas de católicos, leigos ou religiosos, entre os séculos XVIII e XX. O movimento católico leigo sempre foi forte em Minas Gerais favorecido pelas proibições da Coroa Portuguesa em torno da livre circulação de religiosos, considerados suspeitos de contrabandear o ouro das minas. A primeira Santa Casa, a de Vila Rica, surge de uma irmandade. A caridade também é o mote de outro grupo de leigos que teve grande importância no Brasil, especialmente no século XX - os vicentinos. Assinala-se ainda a divulgação dos ideais de caridade de Frederico Ozanam com base na obra de São Vicente de Paula. Por vicentinos é preciso entender tanto o movimento leigo abrigado nas conferências da Sociedade São Vicente de Paula, como os religiosos: os padres lazaristas e as irmãs vicentinas. O terceiro grupo estudado é o dos médicos católicos, fruto do associativismo profissional incentivado pela igreja católica. As Santas Casas com suas irmandades, os vicentinos e o associativismo católico integram movimentos reconhecidos no mundo todo. Nesse contexto social de grande participação católica nas obras de caridade, restava aos médicos integrar o movimento, com o desprendimento dos atendimentos muitas vezes gratuitos e com o esforço para criar hospitais para a população carente. No século XX, a capital de Minas Gerais, embora fruto de decisão de republicanos e positivistas portadores dos ideários da modernidade, continuou se valendo da caridade cristã para tratar dos pobres.

PALAVRAS CHAVE: Hospitais, catolicismo, caridade, medicina.

KEY WORDS: Hospitals, catholicism, charity, medicine.

\section{Introdução}

A assistência aos desvalidos e em especial aos doentes, por muito tempo, esteve associada às ações de caridade da Igreja e de seus seguidores. Em um de seus mais importantes trabalhos, Rosen traça a sociologia histórica 
de uma instituição comunitária - o Hospital. Segundo ele, o hospital que surge no período medieval era essencialmente um instrumento da sociedade para minorar o sofrimento, diminuir a pobreza, erradicar a mendicidade e ajudar a manter a ordem pública ${ }^{1}$. Porter recua um pouco mais essa história e relaciona os primeiros hospitais ao cristianismo que se dissemina no Império Romano. O triunfo da fé cristã teria trazido à tona os cuidados de enfermagem e a invenção do hospital como uma instituição de cuidados à saúde. Afinal «Cristo tinha feito curas milagrosas, dando visão aos cegos e tirando o demônio dos insanos» ${ }^{2}$. Com o cristianismo, a caridade tornou-se uma virtude suprema e os fiéis eram estimulados a cuidar dos necessitados. Após tornar-se religião oficial, graças à conversão do Imperador Constantino, os hospitais apareceram como fundações devotadas e com ordens religiosas dedicadas a servir às pessoas ${ }^{3}$.

Os hospitais de caridade, tanto o hospital tradicional mencionado por Porter ou o medieval de Rosen, eram controlados por religiosos e, muitas vezes, o termo mais adequado para caracterizá-los era o de «albergue», pois, geralmente, funcionavam dentro dos próprios mosteiros, com pouco mais de doze camas e um par de frades encarregados dos cuidados.

Nos países católicos, essas instituições cresceram, nos séculos XVI e XVII, paralelamente ao crescimento da população. Leigos e religiosos trabalhavam bem juntos nos hospitais, embora algumas vezes aparecessem conflitos entre médicos, com suas prioridades, e a enfermagem, com seus fins piedosos. As doações caridosas aos hospitais participavam da cadeia local de proteção, patronagem e poder familiar. Na França, o hôpital général (similar aos abrigos ingleses) emergiu no século XVII como uma instituição destinada a proteger - e não somente confinar- mendigos, órfãos, vagabundos, prostitutas e ladrões, ao lado do doente e do louco. O Hotel Dieu em Paris era mais especificamente projetado como uma instituição de cura e dirigido por ordens religiosas ${ }^{4}$.

Exemplo bem sucedido do hospital católico é a Santa Casa de Misericórdia de Portugal, criada em 1498, com o objetivo expresso de proporcio-

\footnotetext{
1. Rosen, George. Da polícia médica à medicina social: ensaios sobre a história da assistência médica. Rio de Janeiro: Graal; 1980, p. 354.

2. Porter, Roy. Hospitais e cirurgia. In: Cambridge - História Ilustrada da Medicina. Rio de Janeiro: Revinter; 2001, p. 208.

3. Pereira, Nuno Moniz. A assistência em Portugal na Idade Média. Porto, CTT Correios de Portugal; 2005.

4. Porter, n. 3, p. 209.
} 
nar auxílio espiritual e material aos necessitados. A experiência da Santa Casa foi um dos modelos portugueses mais difundidos em suas colônias. A inspiração divina para as obras de caridade aparece no Compromisso, célebre documento da nova confraria, transmitido, por comunicação régia manuelina, às irmandades que tentavam se edificar nas principais cidades do reino, a partir de 1499. A caridade era o fundamento da Irmandade e a Virgem Maria da Misericórdia o grande auxilio espiritual para as tribulações e misérias de que padecem os irmãos em Cristo que receberam o santo batismo.

Segundo Sousa ${ }^{5}$, no cerne da atividade das Misericórdias, estava uma adesão importante à espiritualidade da paixão e a meditação sobre a dimensão protetora de Maria, expressa numa profunda prática penitencial. No Compromisso firmado pelas Misericórdias, o mais importante era o assistencialismo. Para participar do núcleo assistencial, além da postura penitencial, o corpo e o rosto dos confrades deveriam ser cobertos, simbolizando a prática desinteressada da misericórdia. Os confrades deveriam ser bons, virtuosos, de boa fama e estar a «serviço de Deus e do próximo». Não se tratava de obrigação religiosa e moral geral, mas de uma lição normativa concreta, que funcionava com eficácia para especializar o serviço confraternal ${ }^{6}$.

Esse modelo assistencial da Santa Casa chegou ao Brasil, como a todas as colônias portuguesas, ainda no século XVI, mas não se desenvolveu em todo o território como pregava o Compromisso do século XV. As Santas Casas apareceram nas regiões litorâneas, mas tiveram dificuldades em se estabelecer no interior do país, especialmente em Minas Gerais, o que aconteceu somente a partir do século XVIII ${ }^{7}$.

No período colonial, não houve incentivo ao crescimento da atuação de religiosos em Minas Gerais. A ocupação da região teve início com os bandeirantes paulistas, no século XVII. Confirmada a descoberta do ouro, recebeu atenção redobrada da Coroa. A preocupação com a tributação era

5. Sousa, Ivo Carneiro. Da fundação e da originalidade das Misericórdias Portuguesas (1498-1500). Revista Oceanos. Misericórdias: cinco séculos. 1998; 35: 24-39 (24).

6. Sousa, n. 5, p. 36.

7. Russel-Wood, Anthony J. R. Fidalgos e filantropos: a Santa Casa da Misericórdia da Bahia, 15501755. Brasília: UnB; 1981. Boschi, Caio César. Os leigos e o poder: irmandades leigas e política colonizadora em Minas Gerais. São Paulo: Atica; 1986. 
grande, assim como a necessidade de impedir a circulação de riquezas por meio do contrabando.

Combater o contrabando era difícil devido ao movimento de pessoas pela região que ainda estava sendo desbravada. Entre os grupos que mais circulavam estava o dos religiosos. Os padres seculares e regulares estiveram presentes desde o início do povoamento das Minas, por serem considerados indispensáveis à atividade das bandeiras. Proibidos pela Coroa de instalar conventos na região mineradora, fundaram os hospícios destinados ao abrigo de frades missionários. Ainda na primeira metade do século XVIII, foram fundados o hospício de Vila Rica em 1726, os de São João Del Rei e de Sabará em 1740 e o de Mariana em $1750^{8}$.

Os hospícios também foram combatidos. A partir de 1711, a Coroa expediu várias cartas proibindo a instalação e a permanência de clérigos regulares que se encontrassem sem emprego ou préstimo dos missionários, assim como o afluxo de estrangeiros.

Nesse caso, a luta não era contra a Igreja, mas contra os padres ou qualquer um que pudesse circular com ouro irregularmente. Como a Igreja não era responsável pelo pagamento dos religiosos, bastou a Coroa limitar o número de padres na folha de pagamento para diminuir seu afluxo à região.

Em Minas Gerais, a diminuição do número de religiosos provocou o surgimento das irmandades leigas que assumiram não só o controle das igrejas como a assistência a seus filiados. A falta de religiosos e o domínio dos leigos não eram sinais de que a religiosidade católica estivesse fora do cotidiano colonial. A Igreja era responsável por todas as ocorrências da vida civil e privada dos paroquianos, como nascimentos, casamentos e mortes. O predomínio das irmandades sofreu críticas. Temos, por exemplo, a crítica a sua ação em Vila Rica, feita por Auguste de Saint-Hilaire, viajante naturalista francês que esteve no Brasil entre 1816 e 1822:

«Existe em Vila Rica um hospital civil mantido pela irmandade de Misericórdia; mas este estabelecimento apenas atesta a mais deplorável das negligências. Não é para lamentar que na capital de uma região que se diz cristã, e onde tantas somas se despedem para construir igrejas inúteis, não se tenha ainda pensado em oferecer um asilo conveniente à pobreza sofredora? E se os particulares são tão indiferentes ao cumprimento desse dever, não é

8. Figueiredo, Cecília M. Fortes. Religião e religiosidade em Mariana no século XVIII. In: Termo de Mariana: história e documentação. Mariana: Imprensa Universitária; 1998, p. 100. 
para espantar que os governos não tenham tomado a menor disposição para suprir o seu pouco zelo» ${ }^{9}$.

Apesar da veracidade das críticas apresentadas por Saint-Hilaire, a ação das irmandades foi vista com bons olhos pela Coroa portuguesa. Para o governo português, eram importantes aliadas e valia a pena lançar mão de vários estratagemas para obter seu apoio, inclusive seu essencial apoio financeiro ${ }^{10}$. O dinheiro recolhido pelas irmandades servia não só para o assistencialismo, como também para conceder empréstimos aos confrades e assumir obras que, em vários países europeus, já eram assumidas pelo Estado.

Mesmo com tantos obstáculos a sua implantação, as Santas Casas foram as instituições assistenciais mais disseminadas em Minas Gerais nos séculos XVIII e XIX. Por serem, em muitas regiões, o único recurso para uma parcela significativa da população carente, frequentemente lidavam com dificuldades de caixa e eram forçadas a restringir o atendimento, apesar de receberem, às vezes, generosas doações.

As esmolas e doações aumentavam e diminuíam de acordo com o estímulo dos governantes. Num documento de 1778, José Joaquim da Rocha descreve a criação, ascensão e declínio da Santa Casa de Ouro Preto (1738), a partir da concessão ou não de privilégios aos grandes doadores.

«(..) presentemente se acha essa Casa muito pobre, por ser pequeno o seu patrimônio; e o que lhe deu sempre os maiores socorros foram os privilégios que os governantes concedem a um homem de cada freguesia, para nela pedirem para a Santa Casa, e cada um destes, além de esmolas que lhe davam, concorriam da sua parte com o que podia, só a fim de aparecer com avultada esmola, para que lhe sejam conservados os privilégios; porém, como tem havido alguns governadores que aboliram tais privilégios e os que lhe foram sucedendo, se não os lembrarem mais de os conceder em beneficio tão pio, é que entrou a deteriorar a Misericórdia; e se acham em estado mais miserável» ${ }^{11}$.

9. Saint-Hilaire, Auguste de. Viagens pelas províncias do Rio de Janeiro e de Minas Gerais. Belo Horizonte/ São Paulo: Itatiaia/ EDUSP; 1975, p. 72.

10. Boschi, n. 7, p. 106.

11. Rocha, José Joaquim da. Geografia histórica da Capitania de Minas Gerais. Descrição geográfica, topográfica, histórica e política da Capitania de Minas Gerais. Memória histórica da Capitania de Minas Gerais - 1778. Belo Horizonte: Fundação João Pinheiro; 1995, p. 103. 
Sem o comprometimento dos governos coloniais, as instituições convivem com a precariedade e sua manutenção atrela-se ao estímulo à caridade de religiosos e fiéis.

\section{A Renovação do discurso da caridade/misericórdia: o caso dos vi- centinos}

Para se compreender a crítica de Saint-Hilaire ao trabalho das irmandades em Minas Gerais, é preciso que se analise o contexto europeu do final do século XVIII e início do XIX. No final do século XVIII, a Europa assiste aos primeiros movimentos vitoriosos contra o Antigo Regime, com ataques dirigidos à nobreza e ao clero e graves repercussões na atuação da Igreja. A caridade foi substituída pela filantropia. Filantropia é, na língua francesa, um neologismo do século XVIII para designar uma virtude que se considerava natural do ser humano, que é o amor por seu próximo, uma laicização do sentimento da caridade. A caridade é fruto do amor por Deus que leva ao ato de fazer o bem aos outros; a filantropia diz respeito à humanidade. $\mathrm{Na}$ filantropia, as ações dos indivíduos em favor da sociedade são consideradas como um sentimento natural, pois a felicidade pessoal só pode ser assegurada quando reina a prosperidade social.

A filantropia era um valor aos olhos da elite europeia de fins do século XVIII e início do XIX, qualquer que seja sua orientação política. Ela age como um pano de fundo a justificar as ambições nacionais e pessoais, já que os interesses privados eram vistos como coletivos. O sentimento filantrópico deveria nortear as ações do europeu civilizado. ${ }^{12}$ Saint-Hilaire era um bom exemplo do naturalista filantropo do século XIX.

O surgimento da filantropia era só mais um dos perigos que ameaçavam a Igreja nos tempos pós-Revolução Francesa. Assiste-se ao abandono dos princípios católicos como a caridade. O novo mundo, surgido após a revolução, era liberal e industrial.

O processo de descristianização, iniciado com a revolução da França, será nosso parâmetro para o estudo do caso brasileiro, verificado com a separação entre Estado e Igreja, a partir da Proclamação da República em 1889. Apesar de, nas duas efemérides, 1789 e 1889, o processo de mudança

12. Kury, Lorelai. Auguste de Saint-Hilaire, viajante exemplar. Intellèctus. 2003; 2 (2): 2. 
política ter determinado a separação das duas instituições, diferenças devem ser destacadas, como a importância do positivismo, no caso brasileiro.

No século que separa as duas datas, houve sensível mudança de mentalidade, ligada ao surgimento de um mundo mais democrático e industrializado. A Igreja busca caminhos para acompanhar a evolução do antiliberalismo e de seu posicionamento elitista e conservador, mais tarde solidificado no anticomunismo. O conhecimento desse processo é fundamental para a compreensão da terceira via desenvolvida entre nós, a partir da encíclica Rerum Novarum de 1891. Nesse período se destacam pensadores católicos que, em sua maioria, tinham origem na nobreza ou preferência pela monarquia, como Joseph de Maistre, De Bonald e Frederico Ozanam entre outros ${ }^{13}$.

O combate ao mundo moderno era explícito. A Igreja estava entrando em um novo século com suas estruturas seriamente abaladas, principalmente no plano das ideias. Era premente que se cuidasse da produção intelectual da Igreja, caracterizada por pontos que formassem uma nova doutrina católica. Essa nova doutrina, desde o início, demarcou sua posição frente a um novo fenômeno revelado pela Revolução Francesa: o povo. A Igreja devia pronunciar-se no novo contexto social e, em suas primeiras intervenções, o que se destacou foi o elitismo dos pensadores católicos.

Louis Gabriel Ambroise de Bonald (1754-1840) foi um importante representante do laicado francês durante a Restauração (1814-1830). Monarquista fiel aos Bourbons, buscou a fundamentação teórica do tradicionalismo em sua obra «Reflexions Philosophiques». Em seus escritos, existiam a preocupação com a crescente industrialização e o saudosismo do tempo em que a Igreja cuidava do bem- estar de seus fiéis ${ }^{14}$.

$\mathrm{O}$ «tempo antigo», antes das revoluções, era considerado muito mais humano e o assistencialismo da Igreja era apresentado como panacéia para os males. Bonald, enquanto deputado entre 1815 a 1828, proferia discursos onde criticava a Revolução Industrial, pregava a volta das corporações e do assistencialismo como solução para a miséria. O passado absolutista e medieval era sempre melhor que a situação gerada pelas revoluções do século XVIII.

13. Marques, Rita de Cássia. Da Romanização a Terceira Via: a Igreja no Brasil de 1889 a 1945. Minas Gerais: Universidade Federal de Minas Gerais; 1995.

14. Bonaldi, Louis G. A. de. A Revolução Industrial e a miséria. In: Ávila, Fernando Bastos, org. O Pensamento social cristão antes de Marx. Rio de Janeiro: Loyola; 1972, p. 39. 
No século XIX, com o avanço do capitalismo industrial, fica claro para os pensadores católicos que a desigualdade social precisava ser combatida.

No campo prático, Antoine Frederico Ozanam (1813-1855) concentrou seus esforços em agrupar jovens intelectuais católicos numa certa unidade de pensamento e ação católica, as Conferências de São Vicente de Paulo, fundadas em 1833. Era um católico fervoroso que não estava preso às tradições monarquistas, aderiu às ideias republicanas e acreditava na possibilidade de unir o cristianismo à democracia.

Ozanam alertava que a Revolução não eliminou a "pobreza que Deus tanto ama» e, por isso, cabia à Igreja uma grande responsabilidade para com o problema social. Condenava tanto o capitalismo como o socialismo porque ambos tinham uma base materialista e centrava o seu pensamento social na pessoa humana. O pensamento de Ozanam é precursor de boa parte dos tratados de Doutrina Social da Igreja como podemos ver abaixo:

"Que a Igreja de nossos dias possa também arrastar os católicos franceses no caminho que ela lhes abre. Vençamos nossas repugnâncias e nosso ressentimento e voltemo-nos para essa democracia, para esse povo que não conhece ainda. Levemos a ele, não apenas nossos sermões, mas nossa colaboração. Ajudemos o povo, não apenas com esmolas que humilham, mas com nossos esforços para criar instituições capazes de emancipá-lo e promovê-lo» ${ }^{15}$.

Ozanam convocou os jovens católicos a intervirem diretamente na luta social, pois só assim eles poderiam regenerar e França e aliviar as dores de alguns de seus pobres. Foi uma constante, em seu pensamento, o apelo para a dedicação ao povo num momento em que o socialismo começava a mobilizar a juventude. Ozanam liga seu pensamento a um santo: São Vicente de Paula (1581-1660). Além de ser considerado o grande inspirador da caridade cristã, exemplo para os que aspiram praticar a assistência aos pobres, o trabalho de São Vicente de Paula também se destaca por seu «incontido amor afetivo e efetivo» aos que clamam por ajuda ao «Evangelizador, Libertador e Salvador dos Pobres» ${ }^{16}$.

Esse «arauto da misericórdia e da ternura de Deus» considerava os pobres senhores e mestres dos verdadeiros cristãos, sempre acompanhado

15. Ávila, n. 14, p. 236.

16. Campos, C. M. Padre José Isabel da Silva. Espiritualidade de São Vicente de Paulo. Grande Sinal - Revista de Espiritualidade. 1981; 7: 517. 
da inseparável companheira de caridade, Louise de Marillac (1591-1660) co-fundadora da Companhia das Filhas da Caridade, pregava aos seguidores cinco grandes virtudes: simplicidade, humildade, doçura, mortificação e zelo ${ }^{17}$. Essas passariam a ser as metas dos irmãos leigos da Sociedade de São Vicente de Paula, tanto quanto já o eram para os Padres da Missão mais conhecidos como lazaristas - congregação nascida da atuação religiosa de São Vicente de Paula ${ }^{18}$.

O sucesso de sua fórmula assistencialista - as Conferências da Sociedade São Vicente de Paula - pode ser medido no número de jovens intelectuais que foram atraídos, não só na França como em várias partes do mundo inclusive no Brasil, influenciando diversos intelectuais ${ }^{19}$.

Desde o tempo do Brasil-Colônia, com o Padroado (união do Estado e da Igreja), que a Igreja Católica detinha a primazia na assistência aos desvalidos. Com a Proclamação da República em 1889, o Estado torna-se laico e é rompida a aliança com a Igreja gerando a aproximação da Igreja brasileira com a romana, período conhecido como o da romanização. Com a romanização, veio a assimilação de vários preceitos seguidos pelo catolicismo mundial, em especial a incorporação da ação dos católicos em um vigoroso movimento que fomentou diversas iniciativas junto aos mais pobres.

Esse movimento interessa-nos especialmente por seus efeitos sobre a assistência à saúde, campo desde o descobrimento dominado pelas Santas Casas criadas basicamente por irmandades leigas que defendiam a assistência aos pobres como uma obrigação dos católicos exortados a serem caridosos. Nesse cenário, merece destaque a cidade de Belo Horizonte, uma cidade inaugurada em 1897, como sendo um símbolo dos tempos republicanos e dos ideais positivistas, mas ainda fortemente marcada pelo catolicismo.

17. Campos, n. 16, p. 526 .

18. Souza, Marco Antônio de. Caridade e Educação: A Pedagogia do Assistencialismo e a Moralização dos Pobres em Belo Horizonte, 1930-1990. Minas Gerais: Universidade Federal de Minas Gerais; 2001.

19. Até insuspeitos modernistas como Mário de Andrade, tiveram passagem por essas Conferências: «Simpatizante das massas oprimidas, Mário jamais chegaria ao radicalismo anti-religioso, tipo "ópio do povo" como também não se refugiaria nas torres de marfim da burguesia, digamos progressista. Sua breve militância católica foi voltada aos pobres, pertencendo como pertenceu à escola de Frederico Ozanam». Damante, Hélio. Mário de Andrade, católico e vicentino. D. O. Leitura. 1993; 12 (137): 16. 


\section{Cidade salubre não precisa de hospitais?}

Belo Horizonte, capital de Minas Gerais, foi a primeira cidade planejada do Brasil. Nasceu no final do século XIX, símbolo da proposta higiênicosanitária do período. Consideraram-se, em seu planejamento, o bom clima e as boas águas. Projetaram-se ruas largas e casas espaçadas. O conjunto dessas condições favoráveis fazia com que a nova capital ganhasse o status de «cidade salubre». Certos dessa vantagem, embora constasse de uma área selecionada para tal, os engenheiros positivistas que planejaram Belo Horizonte não viam a construção de um hospital como prioridade. Contudo, sua falta acarretou problemas desde os tempos da construção da cidade. A Santa Casa de Sabará era o hospital mais próximo e onde eram tratados os casos graves. No período de 1894-1897, foram atendidas 391 pessoas, pelo convênio entre a Santa Casa e a Comissão Construtora. Apesar do convênio, a instituição atendia com certa dificuldade, visto que sempre enfrentava problemas de caixa e assumia os doentes de outras cidades. O sistema de atendimento gratuito sofria com as crises financeiras e a opção por priorizar os pensionistas da instituição, geralmente membros da comunidade de Sabará, dificultava o tratamento dos belorizontinos.

$\mathrm{Na}$ Santa Casa de Sabará, as restrições de atendimento atingiam especialmente a população mais carente, que sofria com as precárias condições de vida e saúde observadas no período da construção. A nova capital - Belo Horizonte - planejada para sediar o governo estadual, abrigando essencialmente funcionários públicos, estava despreparada para alojar as centenas de trabalhadores encarregados de sua edificação, muitos deles acompanhados das famílias. Como o projeto não definisse local de moradia para essa população trabalhadora, houve uma ocupação desordenada da cidade, com barracões feitos dos mais estranhos materiais, detritos de toda ordem ${ }^{20}$. Em relatório preparado em 1896, o próprio engenheiro-chefe Francisco Bicalho reconhece os sérios problemas sanitários da nova capital, atribuindo-os não a uma falha de planejamento, mas aos maus hábitos da população, que

20. Essa ocupação é tão grande, que, em 1902, o prefeito Bernardo Monteiro transforma, pelo decreto 1.516, a 8a seção urbana (Barro Preto) em região suburbana para abrigar cerca de dois mil operários retirados de 600 cafuas no Leitão e 300 no local denominado Favella. Le Ven, Michel Marie. As classes sociais e o poder político na formação espacial de Belo Horizonte (1893-1914). Minas Gerais: Universidade Federal de Minas Gerais; 1977. 
não primava pelo amor à higiene. Segundo ele, as habitações provisórias comprometiam gravemente a salubridade pública ${ }^{21}$.

Além das precárias condições de alojamento da população operária oriunda de diversos pontos assolados por doenças epidêmicas, o serviço de terraplenagem, fundamental à abertura de ruas e avenidas da nova capital, era também considerado, pelas autoridades da época, um fator de insalubridade. Conforme se acreditava, no processo de revolvimento das terras, matérias orgânicas há muito acumuladas eram expostas, favorecendo o desenvolvimento de toda sorte de germes patogênicos. Estavam, assim, criadas as condições necessárias ao desenvolvimento de epidemias, trazendo «o terror às classes operárias, $\mathrm{o}$ atraso para as obras encetadas e o descrédito para o local escolhido para a nova cidade», como descreve Abílio Barreto.

Belo Horizonte, mesmo depois de inaugurada, ainda mantinha o aspecto de um imenso canteiro de obras e fazia por merecer alcunhas como «Poeirópolis»e «Formigópolis» ${ }^{22}$. Apesar disso, a nova capital, desde seu início, recebeu novos habitantes atraídos por seu clima. De todas as vantagens que a cidade apresentava em relação às outras candidatas, o clima foi certamente o mais importante para a escolha e o desenvolvimento da saúde na nova capital. A tuberculose, um dos principais flagelos dos fins do século XIX e início do século XX, não tinha cura medicamentosa e a transferência dos tísicos para cidades como Belo Horizonte tornou-se corriqueira. O clima seco e frio deu à capital o título de cidade-sanatório, atribuído às localidades que abrigavam grande número de tuberculosos e com isso, começou a receber vários médicos, principalmente da quente e úmida capital brasileira da época, o Rio de Janeiro.

O primeiro médico a chegar a Belo Horizonte, atraído pelo clima e visando a cura da tuberculose, foi Cícero Ribeiro Ferreira Rodrigues (1861-1920). Com cartas de apresentação de políticos mineiros influentes, conseguiu um emprego burocrático na Comissão Construtora, mas, em pouco tempo, já ocupava um cargo numa repartição ligada à área médica.

Cícero Ferreira esteve ligado à institucionalização da medicina em Minas, especialmente em Belo Horizonte. Participou da fundação do Hospital de Isolamento (1911), da Faculdade de Medicina (1911), do Hospital São

21. Barreto, Abilio. Belo Horizonte: memória histórica e descritiva - história antiga e história média. Belo Horizonte: Fundação João Pinheiro/Centro de Estudos Históricos e Culturais; 1995; p. 589.

22. Barreto, n. 21, p. 416. 
Vicente (1920) e, principalmente, da Santa Casa de Misericórdia de Belo Horizonte.

Cícero Ferreira integrava o grupo da elite da cidade, que se reuniu em 21 de maio de 1899, com o objetivo de construir uma "Casa de Caridade». Sob o nome de Sociedade Humanitária da Cidade de Minas (primeira denominação da nova capital) foi criado provisoriamente o serviço hospitalar, com algumas enfermarias improvisadas em barracas e barracões, recebendo auxilio dos governos estadual e municipal. O nome Santa Casa não foi pensado no primeiro momento, tampouco foi criada uma irmandade para esse fim. Possivelmente, o que estava sendo planejado era algo semelhante ao hospital humanitário, como existia na Inglaterra desde o século XVIII.

Por ser desprovida de hospitais, ordens religiosas e orfanatos, a moderna Inglaterra estava em desvantagem em relação à assistência aos pobres, se comparada aos padrões europeus, especialmente dos países católicos. Com o advento do Iluminismo, assistiu ao florescimento da filantropia, secular e religiosa e ao início de muitas instituições. Os novos hospitais fundados na Inglaterra eram dirigidos aos necessitados das paróquias, que seriam tratados pela Lei dos Pobres. Garantir assistência gratuita para o pobre doente, respeitável e merecedor, era algo esperado, confirmando os laços sociais de paternalismo $^{23}$, deferência e gratidão ${ }^{24}$. As paróquias tinham de assumir responsabilidades e, para isso, precisaram apelar para o levantamento de fundos e a criação de instituições caritativas.

No caso de Belo Horizonte, a elite pressionada pelo número surpreendente de pessoas carentes, tomou a iniciativa de criar a «casa de caridade» que, apesar de contar com a participação do prefeito Bernardo Monteiro, não era do Estado. Além do prefeito, destacaram-se, na empreitada, empresários e o vigário da matriz da Igreja de Boa Viagem. Os recursos foram levantados junto à população, especialmente em eventos patrocinados pelas «damas da caridade». Cícero Ferreira foi o único médico na comissão que redigiu os estatutos da «Casa», aprovados pelos sócios fundadores da «Sociedade

23. O paternalismo pode ser entendido como uma concentração de autoridade econômica e cultural. Geremek acredita que o caráter paternalista é um fator que de certa forma desacredita o movimento filantrópico, já que muitas vezes o discurso de socorrer os pobres não passa de mera retórica. Geremek, Bronislaw. A piedade e a forca: a história da miséria e da caridade na Europa. Lisboa: Terramar; 1995, p. 280.

24. Porter, n. 2, p. 213. 
Humanitária da Cidade de Minas», no dia 25 de junho de 1899, em sessão realizada no Salão do Congresso Estadual.

As primeiras enfermarias do hospital foram instaladas provisoriamente em barracas de lona doadas pelo governo do estado e o lote foi doado pela prefeitura de Belo Horizonte, permitindo, assim, que os atendimentos tivessem início em 7 de setembro de 1899. O atendimento nas barracas de lonas, aos poucos, e graças às frequentes campanhas de arrecadação de fundos promovidas pelas senhoras da sociedade, foi transferido para as construções de alvenaria.

Nos estatutos, a arrecadação regular prevista era a contribuição mensal dos sócios, além de jóias, mas isso nunca conseguiu, efetivamente, cobrir as despesas do hospital. Outras formas não convencionais de recursos eram usadas, tais como: as loterias que premiavam com objetos de valores diferentes, renda de espetáculos circenses, corridas de bicicleta no Parque Municipal, doações de roupas e alimentos, e quermesses patrocinadas pelas «zeladoras», mais tarde reunidas na «Associação das Damas de Caridade», responsáveis pelas maiores campanhas de arrecadação ${ }^{25}$.

O estímulo à caridade para com os pobres no campo da medicina teve como uma de suas consequências a expansão das Santas Casas e de outros hospitais e maternidades financiados pela crescente atividade filantrópica, que conquistava a burguesia, principalmente as mulheres. Assim aqueles que não tinham nenhum recurso para se tratar, além dos da medicina popular, passaram a ter acesso aos hospitais.

A pedra fundamental foi lançada em 16 de agosto de 1899, dia da Padroeira da cidade. No ano seguinte, a mudança de nome para Santa Casa de Misericórdia parece ter sido o primeiro passo para a construção de um bom relacionamento entre médicos e Igreja em Belo Horizonte. Mais do que isso, o nome Santa Casa funcionaria como chamariz para atrair o público. A Santa Casa, apesar da precariedade dos atendimentos, era uma instituição tradicional e confiável na prestação de assistência aos pobres. A troca do primeiro nome, de provável inspiração maçônica, ajudou a firmar a vinculação com a religião católica e favoreceu o discurso da caridade, necessário para obter, principalmente, o envolvimento das mulheres.

A criação de um hospital para os pobres, contudo, não foi suficiente para conter os índices de mortalidade por falta de socorros médicos, pois

25. Souza, n. 18. 
a Santa Casa nasceu vinculada à clientela pobre e, como a cidade não tinha outro hospital, foi difícil romper com a ideia de que ali também era lugar para as «pessoas de bem» da sociedade.

Quando o médico Hugo Furquim Werneck chegou à Belo Horizonte em 1906, era o único e o primeiro ginecologista da cidade, logo se integrando ao quadro clínico da Santa Casa. De família tradicional do Rio de Janeiro, escolheu essa especialidade por influência do pai, um dos primeiros e mais conceituados ginecologistas do país. Com passagens pelo exterior, onde fora se tratar da tuberculose, trazia conceitos e técnicas modernas, para o atendimento às mulheres. Certo de que a principal causa da mortalidade materna estava ligada à falta de socorros obstétricos, começa sua luta pela criação de uma maternidade em Belo Horizonte e pela extensão dessa assistência a todas as mulheres. Afinado com o movimento mundial de substituição das parteiras pelos médicos, pregava a criação do hospital como sendo o espaço privilegiado para o atendimento às mulheres ${ }^{26}$.

Em 1909, objetivando mais qualidade ao atendimento e a organização do hospital, Werneck, diretor clínico, convidou freiras alemãs, para trabalharem na Santa Casa que se tornou o primeiro estabelecimento de saúde no Brasil a que as religiosas da Congregação das Irmãs Servas do Espírito Santo, fundada pelo Padre Arnaldo Jansen se vincularam. O contrato de prestação de serviços foi assinando com o Provedor Emigdio Germano, pela instituição hospital, e a Irmã Warburgis, Elizabeth Schmitz, SupervisoraProvincial da Congregação. As irmãs tornaram-se assim responsáveis pela área administrativa, enfermagem, farmácia e cozinha da Santa $\mathrm{Casa}^{27}$.

Inegavelmente a presença de freiras católicas foi um forte ingrediente para a aceitação da instituição hospitalar na cidade, pois sua rigidez e eficiência deram respeitabilidade à instituição, além de reforçar, junto a população, que a Santa Casa era uma instituição católica.

Com a presença das freiras, Hugo Werneck impulsiona seu projeto de ampliação da Santa Casa. Sua primeira conquista foi a inauguração do «Pavilhão Hugo Werneck», em 1910. O prédio possuía dois pavimentos, sendo o primeiro dedicado à clínica cirúrgica de mulheres e outro à Maternidade. Esse importante passo da institucionalização da medicina, contudo, não

26. Marques, Rita de Cássia. A Imagem social do Médico de senhoras no século XX. Belo Horizonte: COOPMED; 2005.

27. Santa Casa Notícias. Entre-guerras e revoluções, sempre a serviço do bem. Belo Horizonte; EDITORIAL; 2002, p. 9. 
foi suficiente para convencer a população dos benefícios do atendimento hospitalar e, por isso, para a construção da maternidade Hilda Brandão foi preciso apelar novamente à caridade. Se, por um lado, a caridade ajudava na construção e na manutenção dos hospitais, a sensibilização da elite para a caridade encontrava algumas dificuldades nos preceitos morais vigentes. A construção da primeira maternidade de Belo Horizonte exemplifica essa dificuldade. As mulheres da elite tinham seus filhos em casa, assistidas por uma parteira e, se o parto se complicasse, o médico era chamado a intervir. A ideia de uma maternidade só poderia, no entender da elite, favorecer àquelas mulheres que tinham seus filhos longe de um lar estabelecido, como, por exemplo, as mães solteiras e prostitutas ${ }^{28}$.

No mundo inteiro, os primeiros hospitais e maternidades foram destinados aos pobres. As motivações do médico para intervir cirurgicamente, após um trabalho de parto demorado, eram diversas: médicas (frente a um grave estreitamento da bacia); éticas (a recusa em matar a criança), religiosas (a vontade de assegurar, ao menos, a saúde eterna da criança); ligadas ao controle moral (no caso de gravidez ilegítima) e à grande importância social que a maternidade passa a ter nos discursos médicos da época moderna. Em Belo Horizonte, no início do século XX, essas também são as motivações de Hugo Werneck para construir a primeira maternidade, conforme podemos observar no discurso de inauguração:

«De fato a maternidade não se destina apenas a socorrer a mulher que vai ser mãe; dar-lhe um asilo onde possa por alguns dias abrigar sua miséria; abrir-lhe um refúgio onde venha esconder as mágoas e o arrependimento de uma falta de que, no momento, ela é a única a trazer os sinais inequívocos da responsabilidade; prevenir e combater pela caridade os desfalecimentos morais e as funestas resoluções do desespero; cercar o berço do recém nascido pobre de cuidados que mais tarde não se poderia ter, o seu programa é mais vasto» ${ }^{29}$.

Católico praticante e pai de uma família numerosa, Werneck soube com o seu discurso apelar para a caridade dos belorizontinos que apoiaram as obras da maternidade, assim como a sua atuação em prol da saúde da mulher. $\mathrm{O}$ discurso católico e o incentivo à caridade na assistência aos

\footnotetext{
28. Marques, n. 26.

29. Werneck, Hugo. Discurso do Professor Werneck por occasião da inauguração da Maternidade. Archivos Mineiros de Medicina. 1916; 1 (2).
} 
mais pobres foram fundamentais para o nascimento e o funcionamento de outros hospitais em Belo Horizonte.

Um dos hospitais que nasceu marcado pelo discurso da caridade e pela forte presença das irmãs de caridade foi o Hospital São Vicente, atualmente o prédio principal do Hospital das Clinicas da Universidade Federal de Minas Gerais (UFMG). A capital planejada para centro administrativo do Estado de Minas Gerais, não contava em seu planejamento com a permanência dos pobres operários que construíram a cidade. Sem área especifica para construírem suas casas, acabaram ocupando áreas irregulares do subúrbio e muitos de seus filhos perambulavam pela ruas. A infância desamparada tornou-se assim, um dos grandes problemas de Belo Horizonte. A preocupação com essa situação ficou evidente no I Congresso Católico Mineiro, realizado em Mariana, no ano de 1910. As principais decisões do Congresso foram registradas no Boletim do Centro da União Popular e Comissão Permanente dos Congressos Católicos de Minas Gerais, reproduzidos por Souza (2004) define a caridade como «uma virtude essencialmente cristã e que as obras de caridade são o efluxo necessário da vida devota».

O Primeiro Congresso Católico procurava explicar como deveria funcionar as instituições de caridade, salientando sempre as relações com o clero e a Igreja. O Congresso pregava que todas as instituições de beneficência tivesse caráter de associação católica e entre outras coisas:

«5) Que enquanto for possível a assistência às necessidades comuns do pobre, conservem seu carater privado, só se utilizando a assistência coletiva quando as circunstancias locais permitirem (...) 7) Que entre as obras de caridade a fundar-se sejam consideradas três classes de pessoas: os enfermos, a infância desvalida e as infelizes arrepentidas» ${ }^{30}$.

Assim orientados os católicos promoveram e participaram ativamente de diversas atividades para recolher fundos e ajudar na construção dos prédios da Santa Casa, da Maternidade Hilda Brandão e do amparo a infância. Em 1919, entre outras iniciativas que tentavam resolver o problema da infância desvalida em Belo Horizonte, surge incentivado por Moncorvo Filho, o Instituto de Proteção e Assistência à Infância e Associação das 
Damas de Assistência de Belo Horizonte ${ }^{31}$. Inaugurado em 15 de maio de 1921, o Hospital São Vicente foi o resultado dos esforços do Instituto de Assistência e Proteção à Infância, com a Faculdade de Medicina, recebendo dela um auxílio de 20 contos em troca da cessão do hospital para o funcionamento das clínicas pediátricas (médica e cirúrgica). Apesar das imensas dificuldades financeiras, o Hospital continuou crescendo com o apoio da caridade e, em 1929, foi instalado um serviço de radiologia.

A ligação com a Faculdade de Medicina estreita-se em 1931 quando a Fundação São Vicente de Paulo, sucessora do Instituto de Proteção à Infância e na época constituída por médicos católicos, fez doações de patrimônio à Faculdade, com o intuito de facilitar a edificação do Hospital das Clinicas. Apesar dessa contribuição fundamental, a construção do Hospital das Clinicas só aconteceu em 1949, com a federalização da Universidade.

Iniciativas isoladas como a de médicos católicos sempre aconteceram, mas se fortaleceram com a criação de uma associação no século XX.

\section{Associação de Médicos Católicos}

Um importante movimento leigo que surgiu no contexto da igreja católica e que atuou na implantação de hospitais em Belo Horizonte foi o dos Médicos Católicos. São Lucas, o evangelista médico, é o santo padroeiro da medicina e sob seu nome se reuniram, no mundo inteiro, médicos católicos. Em 27 de setembro de 1871, foi fundada, na França, uma sociedade São Lucas, sob os auspícios do Papa Leão XIII. Esse papa, mais tarde, revolucionou a doutrina social da Igreja ao propor maior atenção dos católicos com os problemas dos trabalhadores, sendo sua obra mais importante a Encíclica Rerum Novarum, de 1891. Essa encíclica surge numa época em que se encontrava acirrada a luta entre socialismo e capitalismo, e a Igreja propõe a Terceira Via, que pregava a harmonia entre as classes sociais. $\mathrm{O}$ instrumento institucional para viabilizar a Terceira Via seria a corporação,

31. O Instituto de Proteção a Infância integraria uma grande estrutura de atenção a criança, gerando benefícios e oferecendo assistência a muitas famílias pobres, inspirado em modelos da Bélgica, Argentina e Estados Unidos. O Instituto agiria conjuntamente às Damas de Caridade que ficariam encarregadas de funções femininas como confeccionar roupas, organizar festas e arrecadar donativos. Wadsworth, James E. Moncorvo Filho e o problema da infância: modelos institucionais e ideológicos da assistência à infância no Brasil. Revista Brasileira de Historia. 1999; 19 (37): 103-124. 
sua pregação incentivou a organização dos católicos, em grupos específicos. Assim surgiram as associações de operários, estudantes, mulheres, engenheiros e médicos católicos entre outros ${ }^{32}$.

O modelo de associação de médicos católicos expandiu-se. A primeira associação do Brasil foi a Sociedade São Lucas do Rio de Janeiro, fundada em 1904 por Dr. Araújo Penna. Nos anos 1920 e 1930, incentivadas pela própria cúpula da Igreja, as associações de médicos católicos se multiplicaram. O Papa Pio XI foi um grande incentivador da Ação Católica e estimulou especialmente os médicos, como pode ser percebido em uma fala proferida ao receber, em 8 de setembro de 1924, uma peregrinação de médicos católicos da Argentina:

«Na experiência do nosso ministério temos em verdade verificado quanto o médico das almas possa facilitar a obra do médico de corpos; e quanto vice-versa possa o médico dos corpos ser outrossim médico das almas; não indiretamente pelo exercício honesto de sua profissão, mas ainda diretamente. Lembramos-nos, com profunda gratidão, de tais médicos encontrados ao pé do leito dos enfermos que foram verdadeiros precursores do sacerdote na cura das almas. E compreende-se como um médico que queira curar o «homem», e não só o "corpo humano", deva ocupar-se em seus estudos também dos problemas espirituais; pois que são freqüentes no campo médico homens de cultura perfeita, também no terreno dos fenômenos espirituais» ${ }^{33}$.

Em Belo Horizonte, o incentivo papal para que o médico fosse de corpo e de alma, aliado a influência da experiência do Rio de Janeiro foram decisivos para se pensar em criar uma sociedade de médicos católicos, conforme o editorial d'O Horizonte, intitulado «Intellectuaes catholicos»:

«Foi no Rio que se fundou a primeira do Brasil, reunindo alli o que a medicina tem de mais representativo, um desmentido formal a esta corrente afirmação de que a medicina tende a fazer de seus cultores outros tantos materialistas.

Este ano foi S. Paulo que fundou a sua, com festas dignas da significação do acontecimento em que mais uma vez se marca o avanço que a Igreja vai fazendo nos espíritos sérios e ponderados. (...) A ata da inauguração foi

32. Marques, n. 13.

33. Pio XI e L'Azione Católica - Roma, 1929:508, citado por Cunha, Roberto Almeida. O papel do médico na Ação católica. In: Anais do Primeiro Congresso Brasileiro de Médicos Católicos. Fortaleza: EDITORIAL; 1946, p. 136. 
assinada por cinquenta médicos católicos (...) Renovamos agora os nossos votos: queremos ver em breve os nossos médicos católicos - e graças a Deus os temos reunidos numa Associação São Lucas, porque é nestas organizações que repousa uma grande força de ação católica» ${ }^{34}$.

O apelo aos jovens para se engajar na militância católica rendeu muitos frutos em Minas Gerais. A primeira associação foi a «União dos Moços Católicos» que deu origem, em Belo Horizonte, a Sociedade Médica São Lucas, instalada em 4 de abril de 1929, sob a presidência de honra do Arcebispo Dom Antonio dos Santos Cabral e com discursos dos médicos católicos Araújo Penna e Roberto Almeida Cunha.

O secretário geral que assina o convite, Olinto Orsini, era professor de dermatologia e sifilografia da Faculdade de Medicina, presidia o Conselho Superior da «União dos Moços Católicos», dirigia o periódico União dos Moços e, em 1929, começou a dirigir, também, o jornal católico O Horizonte, ou seja, era uma das maiores lideranças do movimento leigo em Minas Gerais ${ }^{35}$. Graças ao empenho de homens como Orsini, e com o apoio decisivo da Cúria de Belo Horizonte, a Sociedade Medica São Lucas foi formalmente instalada com a seguinte composição: Presidente honorário, Dom. Antonio dos Santos Cabral; Presidente. Dr. Borges da Costa; Vice-Presidente, Prof. Almeida Cunha; Secretário Geral Dr. Olyntho Orsini; Secretário Dr. Alberto Cavalcanti e Thesoureiro Dr. Magalhães Gomes ${ }^{36}$.

Com exceção do Dr. Alberto Cavalcanti, todos os demais médicos eram professores da Faculdade de Medicina, desde a primeira turma formada. O cargo de presidente honorário para o arcebispo da cidade, Dom Cabral, reforça que antes de ser uma associação de médicos, era uma associação de católicos. Enquanto na Associação Médico-Cirurgica de Minas Gerais, Olyntho Orsini apresentava, no dia 18 de novembro de 1928, uma observação sobre tratamento dos «processos elefantíacos da perna pela operação de Moreschi-Marianni», na Sociedade São Lucas os temas prediletos eram educação sexual, aulas de religião nas escolas públicas, moral e política.

$\mathrm{O}$ incentivo ao desenvolvimento do movimento leigo fez crescer o prestígio de lideranças como Roberto Almeida Cunha, professor da Faculdade de Medicina, que discursou na instalação da Sociedade Médica

\footnotetext{
34. O Horizonte; 24 Nov 1928, p. 1.

35. O Horizonte; 8 Abr 1929, p. 1.

36. O Horizonte; 8 Abr 1929, n. 35.
} 
São Lucas e, mais tarde, tornou-se Presidente da Junta Arquidiocesana da Ação Católica ${ }^{37}$. Em seu discurso, Almeida Cunha ataca o racionalismo e reafirma a importância de uma associação exclusiva de médicos católicos:

«Hoje que a peste terrível do racionalismo, indumentada em aurea roupagem de liberalismo e superioridade intelectual se apodera dos meios dirigentes da sociedade humana, o nosso papel é delicado, é difícil, é sublime! Surgem a cada instante instituições liberais que se jactam de seu respeito às Confissões religiosas, paradoxalmente exigindo que cada um as deponha no vestiário ao penetrar no ambiente das deliberações.

A Sociedade São Lucas é particularmente preciosa porque espatifa a hypocrisia d'essa pseudo-superioridade. Associados de São Lucas são os catholicos praticantes, médicos e basta» ${ }^{38}$.

Seguindo o exemplo de outras associações de classe que surgiram sob a influência do corporativismo, os médicos também formaram uma Corporação de Médicos Católicos, na década de 1930. Os assuntos discutidos na Corporação de Médicos Católicos eram variados, mas os temas médicos sempre eram entremeados pela religião.

Paralelamente às discussões de temas médicos e religiosos, a Corporação se dedicava à assistência aos desvalidos e uma de suas maiores realizações foi a criação do Hospital São Francisco de Assis prestando serviços á população mais carente. A corporação era filiada ao Conselho Metropolitano de Belo Horizonte, da Sociedade São Vicente de Paulo.

O corporativismo médico de Belo Horizonte personificado na Corporação de Médicos Católicos, tinha como destaque o médico Joaquim Pedro de Menezes Furtado, mais conhecido nos meios vicentinos como Dr. Furtado de Menezes. Sua trajetória na militância católica começou com seu ingresso na Sociedade São Vicente de Paulo, de Ouro Preto, em 1895. Em 1935, com uma liderança inconteste junto aos católicos de Minas Gerais, participa da fundação de várias corporações católicas como a dos médicos, dos engenheiros, dos viajantes, dos advogados e dos contabilistas.

Não foram encontrados os registros completos da Corporação de Médicos Católicos. Sabe-se que os médicos eram muito atuantes e estavam dispersos em diversas associações. Não se desmobilizaram. A efemeridade de alguns nomes de associações não significava desarticulação. O livro

37. O Diário; 14 Mar 1937.

38. O Horizonte; 11 May 1929, p. 2. 
de atas de uma dessas associações, a da Sociedade Médica da Creche do Menino Jesus, é bem ilustrativo dessa variação de nomes para uma mesma agremiação. A primeira ata é de 31 de março de 1935, quando se deu a fundação da Sociedade. No mesmo livro, em 24 de agosto do mesmo ano, a ata já se refere à oitava sessão da Sociedade Médica São Vicente. Um ano depois de fundada em 3 de março de 1936, na 13a sessão, o nome da associação é Academia São Lucas, denominação que permanece até 21 de julho de 1944, data da última ata de reunião encontrada.

Além da variedade de nomes de uma mesma agremiação, os médicos católicos agrupavam-se nos hospitais em que trabalhavam. Foram encontradas referências a pelo menos três dessas associações: a do hospital São Francisco, do Hospital Militar e da creche Menino Jesus. Um exemplo é a Sociedade Cirúrgica do Hospital Militar, que era conduzida pelo Professor de Clínica Médica da Faculdade de Medicina, Braz Pellegrino. Em 1936, no II Congresso Eucarístico, ocorrido em Belo Horizonte, Pellegrino esteve encarregado do serviço de saúde ${ }^{39}$.

$\mathrm{Na}$ biblioteca da Cúria Metropolitana de Belo Horizonte existem documentos sobre ação do grupo de médicos que criou o Hospital São Francisco, ligado aos vicentinos, e a fundação do Hospital Nossa Senhora de Lourdes, em 1948, na cidade de Nova Lima, vizinha à Belo Horizonte.

O grande edifício destinado ao hospital São Francisco foi feito para comportar inicialmente 80 leitos e aproveitou o velho barracão de uma creche. Sua direção interna foi entregue às Irmãs Carmelitas da Divina Providencia, mantendo serviços de policlínica (11 leitos), laboratório, raiosX, Farmácia, Maternidade e Lactário. Um ano depois de criado, em 1937, sua policlínica atendeu 10.089 doentes, e, em dietética, a 14.627 crianças que receberam 59.080 mamadeiras.

Nos últimos anos da década de 1930, em Belo Horizonte, os médicos católicos organizados manifestavam-se por vários canais de comunicação. $\mathrm{O}$ avanço de novos grupos de médicos ligados a outros interesses que não os católicos, como os influenciados pela medicina americana, financiados pela Fundação Rockefeller, exigia dos católicos mais do que simplesmente parecerem católicos. Aos médicos católicos não bastava frequentar missas e mostrarem-se piedosos. Os contemporâneos da Ação Católica precisaram militar, pertencer à Corporação dos Médicos Católicos. O apoio do Arce- 
bispo era irrestrito a esses profissionais e ainda era grande a influência da Igreja Católica na cidade.

O movimento dos médicos católicos cresceu em todo o país e, em 1946, aconteceu o Primeiro Congresso Brasileiro de Médicos Católicos, em Fortaleza/CE. Esse Congresso contou com a adesão de médicos e instituições médicas de vários estados, como Minas Gerais, Pernambuco, Rio de Janeiro, Rio Grande do Norte e São Paulo, além de contar com a adesão do episcopado de todo o país. Nas sessões, tanto de estudo quanto as solenes, foram discutidos assuntos de interesse científico-religioso e o problema da concepção espiritual da vida, à luz da medicina e da religião católica ${ }^{40}$.

O único hospital criado por uma corporação de médicos católicos foi o Hospital São Francisco, mas católicos atuantes ou mesmo ateus que não desprezavam o valor cristão da caridade, tão acalentado pelos católicos de Belo Horizonte, estiveram a frente das seguintes instituições da criação da capital até os anos de 1940.

\begin{tabular}{lc}
\hline INSTITUIÇÃO & DATA \\
\hline Santa Casa de Belo Horizonte & 1899 \\
Instituto de Geriatria Afonso Pena & 1912 \\
Maternidade Hilda Brandão & 1916 \\
Hospital São Geraldo & 1920 \\
Hospital São Vicente & 1921 \\
Hospital São Lucas & 1922 \\
Sanatorio Morro das Pedras/ Hospital Madre Teresa & 1928 \\
Hospital Sanatorio Imaculada Conceição & 1934 \\
Hospital São Francisco & 1936 \\
Hospital Felício Rocho & 1942 \\
Hospital da Baleia & 1944 \\
Hospital Maria Guimarães/Moradia dos Médicos Residentes & 1944 \\
Hospital da Cruz Vermelha & 1947 \\
\hline
\end{tabular}

Apesar do predomínio dos católicos, outros grupos de médicos também crescem ao longo da primeira metade do século XX e, em alguns momentos, foram inevitáveis os choques entre seus seguidores, numa disputa de espaço nas instituições médicas e na sociedade em geral. Era o embate de 
médicos católicos militantes e os «ateus». Nas décadas de 1940 e 1950, entram em ação médicos de outras crenças que se unem para criar hospitais que respeitavam seus princípios como o Hospital Evangélico (1957) e o Hospital Espírita André Luiz (1949), mas esse é assunto para outro artigo.

\section{Agradecimientos}

Agradecimentos à Coordenação Nacional do Projeto REDE BRASIL, especialmente Gisele Sanglard pela atenção e compreensão. Aos pesquisadores e bolsistas do projeto Anny J. T. Silveira, Betânia G. Figueiredo, Cecilia Luttembarck de O. L. Rattes, Evandro Guilhon, Claudia Marun M. Martins, Huener Gonçalves Silva e Junnia Alvarenga de Oliveira. 
